\title{
Training Characteristics, Personal Factors and Coping Strategies Associated with Burnout in Junior Doctors: A Multi-Center Study
}

\author{
Nurhanis Syazni Roslan 1,*(D), Muhamad Saiful Bahri Yusoff ${ }^{1}$, Asrenee Ab Razak ${ }^{2}$, Karen Morgan ${ }^{3,4} \oplus$, \\ Nor Izzah Ahmad Shauki ${ }^{5}$, Anjanna Kukreja ${ }^{6}$, Norashidah Rahmat ${ }^{7}$, Chin Ri Wei Andrew ${ }^{8}$, \\ Muhammad Fikri Shaharudin Basri ${ }^{1}$, Abdullah Shamshir Abd Mokti ${ }^{9}{ }^{\circledR}$, Nur Haziyah Md Yazid ${ }^{10}$, \\ Munirah Ismail ${ }^{11}$ (D) and Pangie Bakit ${ }^{11}$
}

check for

updates

Citation: Roslan, N.S.; Yusoff, M.S.B.; Ab Razak, A.; Morgan, K.; Ahmad Shauki, N.I.; Kukreja, A.; Rahmat, N.; Andrew, C.R.W.; Shaharudin Basri, M.F.; Abd Mokti, A.S.; et al. Training Characteristics, Personal Factors and Coping Strategies Associated with Burnout in Junior Doctors: A Multi-Center Study. Healthcare 2021, 9 , 1208. https://doi.org/10.3390/ healthcare 9091208

Academic Editor: Alyx Taylor

Received: 5 July 2021

Accepted: 10 September 2021

Published: 14 September 2021

Publisher's Note: MDPI stays neutral with regard to jurisdictional claims in published maps and institutional affiliations.

Copyright: (c) 2021 by the authors. Licensee MDPI, Basel, Switzerland. This article is an open access article distributed under the terms and conditions of the Creative Commons Attribution (CC BY) license (https:// creativecommons.org/licenses/by/ $4.0 /)$.
1 Department of Medical Education, School of Medical Sciences, Universiti Sains Malaysia, Kota Bharu 16150, Malaysia; msaiful_bahri@usm.my (M.S.B.Y.); mfikri94@yahoo.com (M.F.S.B.)

2 Department of Psychiatry, School of Medical Sciences, Universiti Sains Malaysia and Hospital USM, Universiti Sains Malaysia, Kota Bharu 16150, Malaysia; asrenee@usm.my

3 Perdana University-Royal College of Surgeons in Ireland School of Medicine, Perdana University, Kuala Lumpur 50490, Malaysia; karenmorgan@perdanauniversity.edu.my

4 Department of Health Psychology, Royal College of Surgeons in Ireland, D02 YN77 Dublin, Ireland

5 Institute for Health Systems Research, National Institutes of Health, Ministry of Health, Shah Alam 40170, Malaysia; drizzah@moh.gov.my

6 Department of Medicine, University Malaya Medical Centre, Kuala Lumpur 59100, Malaysia; anjanna@ummc.edu.my

7 Department of Pathology, Hospital Sultanah Aminah Johor Bahru, Ministry of Health, Johor Bahru 80100, Malaysia; rashidah_89@yahoo.com

8 Department of General Surgery, Hospital Queen Elizabeth, Kota Kinabalu, Ministry of Health, Kota Kinabalu 88200, Malaysia; andrew9329@gmail.com

9 Department of General Medicine, Hospital Kuala Lumpur, Ministry of Health, Kuala Lumpur 50586, Malaysia; ab.shamshir@gmail.com

10 Hospital Tunku Azizah, Jalan Raja Muda Abdul Aziz, Kampung Baru, Ministry of Health, Kuala Lumpur 50300, Malaysia; hazichang@gmail.com

11 Institute for Health Management, National Institutes of Health, Ministry of Health, Shah Alam 40170, Malaysia; munirahismail@moh.gov.my (M.I.); pangiebakit@moh.gov.my (P.B.) * Correspondence: nurhanis_syazni@usm.my

Abstract: Physician burnout has been recognized as a public health crisis. However, there is a paucity of burnout studies in the context of medical internship. We assessed the prevalence and relationship between various training characteristics, personal variables, resilience, and coping with burnout in a cross-sectional study involving 837 interns from ten hospitals across Malaysian healthcare system. The instrument package included demographic questions, the Connor-Davidson Resilience Scale, Brief COPE and the Copenhagen Burnout Inventory. A total of 754 (90.1\%) interns completed the inventories. We found a high prevalence of personal-related $(73.3 \%)$, work-related $(69.1 \%)$, and patient-related (43.4\%) burnout among Malaysian interns. Multivariable analysis showed female gender (odds ratio (OR):1.50; 95\% confidence interval (CI): 1.02-2.20), prior work experience (OR: 1.56; 95\% CI: 1.05-2.30), and irregular spirituality routines (OR: 1.97; 95\% CI: 1.30-2.99) were associated with increased odds of personal-related burnout. Irregular spirituality routines (OR: 2.24; 95\% CI: 1.49-3.37) were associated with work-related burnout, while living with other people (OR: 1.77; 95\% CI: 1.15-2.73) was associated with patient-related burnout. Lower resilience levels and avoidant copings were associated with personal-, work-, and patient-related burnout. Burnout prevalence among interns is high. The findings support the value of individual-targeted alongside organizational-targeted intervention in burnout reduction. As burnout is prevalent in both years of internship training, ongoing burnout prevention and wellbeing measures are deemed necessary.

Keywords: junior doctor; internship; resident; burnout; well-being; resilience; coping; medical education 


\section{Introduction}

Burnout can be defined as work-related, multi-dimensional psychological syndrome that can be characterized by exhaustion, depersonalization and a reduced sense of personal accomplishment [1,2]. Recent systematic review reported an alarming burnout prevalence among physicians (up to $80.5 \%$ ) [3]. Burnout was shown to be more prevalent in physicians at various stages of medical training than in their peers from the general population $[4,5]$.

Burnout can be driven by various long-term stressors such as heavy workload, long hours, required use of electronic medical records, lack of job autonomy and poor interpersonal relationship [6,7]. In a person who experienced burnout, the enthusiasm turned to exhaustion, the fulfilling involvement became cynicism and the efficiency declined to inefficacy [1]. Although very few studies have examined the long-term impacts of burnout, a growing body of evidence have linked burnout with patient care practices (increased medical errors, longer recovery time, reduced patient satisfaction, and reduced perceived safety), organizational performance indicators (reduced productivity, increased turnover and costs) and physician health (increased substance abuse, depression and accidents) $[7,8]$.

On top of the established factors mentioned above, several studies have explored burnout association with medical specialties and length of training experience, giving mixed results [7-11]. Interestingly, although the work environment has been thought of as the main contributor to burnout, some personal characteristics and 'less-trait' aspects, such as education, were also found to influence burnout through workload perception [5,12]. Conversely, resilience and spirituality have been increasingly recognized in mitigating burnout through increased insights, self-care and engagement in positive behaviors $[13,14]$. Studies also suggested that certain coping mechanisms may have positive or negative impacts on physician burnout [14-16].

While many studies of burnout focused on medical students, residents and specialized physicians, there have been few studies on medical interns. Internship is an important step in physician's career where it serves as the transition phase from the protected environment of student years to patient care responsibilities. The phase often coincides with major life milestones such as first job, relationship, childbirth and was found to have the highest attrition as compared to the other training stages $[17,18]$. Burnout was initially proposed to be a late-career syndrome, but growing evidence suggested that younger physicians are actually more at risk to develop burnout [19].

Under the Medical (Amendment) Act 2012, all medical graduates in Malaysia are required to undergo two years of internship training prior to full registration in designated training hospitals $[20,21]$. During this mandatory training, medical interns or house officers rotate across five compulsory rotations (medicine, surgery, pediatric, obstetrics and gynecology and orthopedic), and one elective rotation (emergency medicine, anesthesiology, primary care or psychiatry). Each rotation spans for four months. Although internship is ideally a formative time of professional development, interns are expected to take increasing responsibility for patient care and equip themselves with appropriate knowledge, skills and attitudes. This overwhelming responsibility may set the stage for interns to develop mental health problems and burnout [22].

A previous study on Malaysian interns in a single institution university hospital using Maslach Burnout Inventory (MBI) revealed a burnout prevalence of 26.5\% [23]. Having said that, internship training has since changed to a contract scheme, capped at $60 \mathrm{~h}$ per week with a revised assessment system. Some institutions have introduced intern shadowing program in the final year curriculum where medical students are given some responsibility to patient care to improve the work preparedness of the graduates [24] A study in the United Kingdom found that intern shadowing is associated with a lower anxiety level among interns [25]. However, less is known whether intern shadowing reduce the occurrence of burnout among interns.

Building on the above conceptual framework and lack of recent data, we set out to investigate the prevalence of burnout and its relationship with various training characteristics, and personal variables among interns in Malaysia. We hypothesized that certain 
training variables (e.g., rotation and length of experience in internship) and personal factors (e.g., gender, marital status, undergraduate training background, previous extracurricular involvement, work experience, spirituality practices, support at home, coping mechanism, and resilience level) have significant associations with burnout.

\section{Materials and Methods}

\subsection{Study Design}

The study utilized a multi-centre cross-sectional design.

\subsection{Study Participants}

During the study conception, there were 11,706 interns in 46 training hospitals. Using stratified cluster sampling [26], we selected a total of ten training hospitals across all six network zones in the Malaysian healthcare system to represent the geographical distributions (Central, North, South, East, Sabah and Sarawak), variation in patient care needs, and Ministry of Health/Ministry of Education training hospitals.

As there was no prior study in the population that measures on burnout, we adopted the sample size calculation formula for a known population size and unknown population standard deviation [27]. However, as the study utilized stratified cluster sampling, a correction factor (design effect of 1.8) was applied to consider for intra cluster correlation effect [28]. After including a non-response rate of $20 \%$, the final required sample size was 837 interns. In order to better represent the intern population, we determined the sample size for each stratum (network zone) based on its stratum size.

\subsection{Study Tools}

To examine the complex array of variables that could contribute to intern's burnout, we developed the demographic questions based on the conceptual framework discussed above. The survey questions covered personal demographics (gender, marital status, undergraduate academic result, working experience prior to internship, spirituality routine, and available support at home), undergraduate training background (local versus abroad, intern shadowing, and extracurricular involvement) and training demographics (current rotation and length of experience through internship). As Malaysia is a multi-racial country [29], we gave some descriptors of regular versus irregular spirituality routines based on several major religions professed in the country.

The survey also included 3 validated instruments: Connor-Davidson Resilience Scale (CD-RISC) [30], Brief COPE [31], and the Copenhagen Burnout Inventory (CBI) [32]. The ten-items CD-RISC is an instrument to measure resilience and has been validated with Cronbach's alpha coefficient of 0.85 [30]. However, our pilot study of a sample of Malaysian interns failed to verify the ten-items model but provided an acceptable model fit for a nine-items / one-construct model with reliability Cronbach's alpha coefficient of 0.92 . Thus, we performed the analysis using nine-items version with answers scored on a scale of 1 to 5 , where a higher score indicates greater resilience.

Brief COPE is a 28-items inventory that measures 14 coping strategies with answers scored on a scale of 1 to 4 . It has been validated with the average subscale reliability coefficients of 0.68 [31]. A recent Brief COPE study among caregivers proposed four dimensions of coping: problem-solving, positive thinking, social support, and avoidance [33]. As avoidant coping has been correlated with burnout [14,16], we focused the analysis using ten items of avoidant coping that measure behavioral disengagement, denial, self-blame, self-distraction, and substance abuse. We treated the scores dichotomously where subdomain score of less than 4 were considered as less-utilized coping strategies while score ranging from 5 to 8 were taken as commonly used coping strategies.

The CBI is a freely accessible tool in the public domain that assesses burnout using strong psychometrics. In contrast to MBI [1,7], CBI regards fatigue and exhaustion as the core components of burnout [32]. The CBI specifies its measurement to three spheres of participants' life that are attributed to exhaustion: personal-related (six items), work-related 
(seven items) and patient-related (six items) with reliability coefficients of 0.85 to 0.87 for each subscale. Each item is rated on a scale of 0 (never/to a very low degree) to 100 (always / to a very high degree) $[7,32]$. We treated the continuous scores dichotomously, where an established average score of 50 or above for each subscale was treated as burnout [34].

\subsection{Data Collection and Ethical Issues}

The data collection took place between 20 July 2018 to 19 January 2019. We performed paper-based data collection as the survey took an average of $20 \mathrm{~min}$ to fill in and an online survey of similar length has been shown to have a 20-40\% additional rate of dropout [35]. We obtained the names of interns working in the participating hospitals via clinical unit or through each department that conducts internship training. We approached the head of interns from each department and scheduled several sessions to suit both day and night shifts. Several data collection sessions were conducted outside interns' working hours to accommodate the intern's schedule. The data collection session was conducted by the primary researcher or a research assistant neither whom had any working authority or supervisory role on the interns. Participation was completely voluntary, anonymous and written informed consent were obtained from all participants. There were no supervisor or hospital authorities that were present during the session and no identification were made for any interns who refuse participation. All participants received an honorarium of 10 dollars as a token of appreciation for their participation.

\subsection{Statistical Analysis}

For primary analysis, we used descriptive statistics to determine overall burnout prevalence for each subscale and to evaluate prevalence based on each demographic characteristic and on avoidant coping strategies. We used simple logistic regression to examine the relationship of burnout with each variable. For multivariable analysis, we performed binary logistic regression to predict the effect of independent variables on each subscale of burnout. We detected no collinearity for any independent variables, and no variables were removed from the multivariable analysis except for rotation characteristics. All statistical analyses were performed using SPSS version 27 (IBM Corp., Armonk, NY, USA).

\section{Results}

Out of 837 invited participants, 754 (90.1\%) completed the inventories. The nonresponse rate can mainly be attributed to scheduling issues. The mean age of the participants was $26.6 \pm 1.4$ years. Characteristics of the participants corresponds to the studied population in terms of zone distribution. Participants were less likely to be male (36.3\%) and this followed the national profile that reported $60 \%$ of Malaysian physicians are female [36]. A total of 53.7\% participants were in the first year of training, while $46.3 \%$ were in the second year. Fewer participants (4.2\%) came from anesthesiology rotation, as it was an alternative rotation to emergency medicine. Other demographics distribution can be found in Table 1.

Table 1. Training characteristic, personal demographics and undergraduate training background for the participants enrolled in the study $(n=754)$.

\begin{tabular}{ccc}
\hline Demographic Characteristics & $\boldsymbol{n ( \% )}$ & $\begin{array}{c}\text { Actual Distribution } \\
\text { in June 2018 (\%) }\end{array}$ \\
\hline Zone distribution & & \\
Central & $306(40.6)$ & $4364(37.3)$ \\
North & $142(18.8)$ & $1925(16.4)$ \\
East & $134(17.8)$ & $1873(16.0)$ \\
South & $63(8.4)$ & $1768(15.1)$ \\
Sabah & $52(6.9)$ & $896(7.7)$ \\
Sarawak & $57(7.6)$ & $880(7.5)$ \\
\hline
\end{tabular}


Table 1. Cont.

\begin{tabular}{|c|c|c|}
\hline Demographic Characteristics & $n(\%)$ & $\begin{array}{l}\text { Actual Distribution } \\
\text { in June } 2018(\%)\end{array}$ \\
\hline \multicolumn{3}{|l|}{ Training characteristics: Rotation } \\
\hline Medicine & $126(16.7)$ & \\
\hline Surgery & $136(18.0)$ & \\
\hline Pediatric & $85(11.3)$ & \\
\hline Obstetrics and Gynecology & $101(13.4)$ & \\
\hline Orthopedic & $193(25.6)$ & \\
\hline Emergency Medicine & $81(10.8)$ & \\
\hline Anesthesiology & $32(4.2)$ & \\
\hline \multicolumn{3}{|l|}{ Experience in internship } \\
\hline Less than 1 year & $405(53.7)$ & \\
\hline 1 to 2 years & $349(46.3)$ & \\
\hline \multicolumn{3}{|l|}{ Personal demographics: Gender } \\
\hline Male & $274(36.3)$ & \\
\hline Female & $480(63.7)$ & \\
\hline \multicolumn{3}{|l|}{ Marital status } \\
\hline Single & $628(83.3)$ & \\
\hline Married & $126(16.7)$ & \\
\hline \multicolumn{3}{|l|}{ Final undergraduate academic results } \\
\hline Honors & $421(55.8)$ & \\
\hline Pass & $333(44.2)$ & \\
\hline \multicolumn{3}{|l|}{$\begin{array}{l}\text { Extracurricular involvements in } \\
\text { undergraduate years }\end{array}$} \\
\hline Yes & $417(56.3)$ & \\
\hline No & $337(44.7)$ & \\
\hline \multicolumn{3}{|l|}{ Work experience prior to internship } \\
\hline Yes & $510(67.6)$ & \\
\hline No & $244(32.4)$ & \\
\hline \multicolumn{3}{|l|}{ Spirituality routine } \\
\hline Regular & $501(66.4)$ & \\
\hline Irregular & $253(33.6)$ & \\
\hline \multicolumn{3}{|l|}{ Living with someone at home } \\
\hline Yes & $613(81.3)$ & \\
\hline No & $141(18.7)$ & \\
\hline \multicolumn{3}{|l|}{ Undergraduate training background } \\
\hline Local universities & $441(58.5)$ & \\
\hline Abroad universities & $313(41.5)$ & \\
\hline \multicolumn{3}{|c|}{ Intern shadowing in undergraduate years } \\
\hline Yes & $170(22.5)$ & \\
\hline No & $584(77.5)$ & \\
\hline
\end{tabular}

\subsection{Prevalence of Burnout among Interns}

As illustrated in Table 2, the overall prevalence of burnout for Malaysian interns were $73.3 \%$ (personal-related), $69.1 \%$ (work-related) and $43.4 \%$ (patient-related). Personal- and patient-related burnout were highest for interns in emergency medicine rotation $(79.0 \%$ and $54.3 \%)$, while work-related burnout was highest for interns in Medicine rotation (76.2\%). Anaesthesiology interns had the lowest prevalence of burnout across all three domains. Personal- and work-related burnout were higher in first-year interns while patient-related burnout was higher in second year interns. Personal-, work-, and patient-related burnout were found to be more prevalent in certain characteristics (female, married, "pass" results in undergraduate exam in contrast to honours, no extracurricular involvement in undergraduate years, working experience prior to internship, irregular spirituality routines 
and living with someone at home). Participants who had their undergraduate training at local institutions or who had completed no intern shadowing were found to have a higher prevalence of burnout across the three domains. Burnout was also found to be more prevalent among participants who used any kind of avoidant coping.

Table 2. Burnout prevalence for overall, training characteristics, personal demographics, undergraduate training background and avoidant coping $(n=754)$.

\begin{tabular}{|c|c|c|c|}
\hline Demographic Characteristics & $\begin{array}{c}\text { Personal } \\
\text { Related } \\
\text { Burnout } \\
n(\%)\end{array}$ & $\begin{array}{c}\text { Work Related } \\
\text { Burnout } \\
n(\%)\end{array}$ & $\begin{array}{c}\text { Patient Related } \\
\text { Burnout } \\
n(\%)\end{array}$ \\
\hline Overall & $553(73.3)$ & $521(69.1)$ & $327(43.4)$ \\
\hline \multicolumn{4}{|l|}{ Training characteristics } \\
\hline \multicolumn{4}{|l|}{ Rotation } \\
\hline Medicine & $98(77.8)$ & $96(76.2)$ & $57(45.2)$ \\
\hline Surgery & $99(72.8)$ & $92(67.6)$ & $59(43.4)$ \\
\hline Paediatric & $60(70.6)$ & $56(65.9)$ & $32(37.6)$ \\
\hline Obstetrics and Gynaecology & $69(68.3)$ & $66(65.3)$ & $36(35.6)$ \\
\hline Orthopaedic & $144(74.6)$ & $134(69.4)$ & $92(47.7)$ \\
\hline Emergency Medicine & $64(79.0)$ & $58(71.6)$ & $44(54.3)$ \\
\hline Anaesthesiology & $19(59.4)$ & $19(59.4)$ & $7(21.9)$ \\
\hline \multicolumn{4}{|l|}{ Experience in internship } \\
\hline Less than 1 year & $298(73.6)$ & $290(71.6)$ & $166(41.0)$ \\
\hline 1 to 2 years & $255(73.1)$ & $231(66.2)$ & $161(46.1)$ \\
\hline \multicolumn{4}{|l|}{ Personal demographics } \\
\hline \multicolumn{4}{|l|}{ Gender } \\
\hline Male & $194(70.8)$ & $188(68.6)$ & $115(42.0)$ \\
\hline Female & $359(74.8)$ & $333(69.4)$ & $212(44.2)$ \\
\hline \multicolumn{4}{|l|}{ Marital status } \\
\hline Single & $457(72.8)$ & $428(68.2)$ & $264(42.0)$ \\
\hline Married & $96(76.2)$ & $93(73.8)$ & $63(50.0)$ \\
\hline \multicolumn{4}{|l|}{ Final undergraduate academic results } \\
\hline Honours & $307(72.9)$ & $290(68.9)$ & $181(43.0)$ \\
\hline Pass & $246(73.9)$ & $231(69.4)$ & $146(43.8)$ \\
\hline \multicolumn{4}{|l|}{$\begin{array}{l}\text { Extracurricular involvements in } \\
\text { undergraduate years }\end{array}$} \\
\hline Yes & $298(71.5)$ & $280(67.1)$ & $166(39.8)$ \\
\hline No & $255(75.7)$ & $241(71.5)$ & $161(47.8)$ \\
\hline \multicolumn{4}{|l|}{ Work experience prior to internship } \\
\hline Yes & $385(75.5)$ & $361(70.8)$ & $221(43.3)$ \\
\hline No & $168(68.9)$ & $160(65.6)$ & $106(43.4)$ \\
\hline \multicolumn{4}{|l|}{ Spirituality routine } \\
\hline Regular & $351(70.1)$ & $325(64.9)$ & $217(43.3)$ \\
\hline Irregular & $202(79.8)$ & $196(77.5)$ & $110(43.5)$ \\
\hline \multicolumn{4}{|l|}{ Living with someone at home } \\
\hline Yes & $452(73.7)$ & $426(69.5)$ & $278(45.4)$ \\
\hline No & $101(71.6)$ & $95(67.4)$ & $49(34.8)$ \\
\hline \multicolumn{4}{|l|}{ Undergraduate training background } \\
\hline Local universities & $325(73.7)$ & $305(69.2)$ & $196(44.4)$ \\
\hline Abroad universities & $228(72.8)$ & $216(69.0)$ & $131(40.1)$ \\
\hline \multicolumn{4}{|l|}{$\begin{array}{l}\text { Intern shadowing in undergraduate } \\
\text { years }\end{array}$} \\
\hline Yes & $118(69.4)$ & $116(68.2)$ & $66(38.8)$ \\
\hline No & $435(74.5)$ & $405(69.3)$ & $261(44.7)$ \\
\hline
\end{tabular}


Table 2. Cont.

\begin{tabular}{cccc}
\hline Demographic Characteristics & $\begin{array}{c}\text { Personal } \\
\text { Related } \\
\text { Burnout } \\
\boldsymbol{n} \mathbf{( \% )}\end{array}$ & $\begin{array}{c}\text { Work Related } \\
\text { Burnout } \\
\boldsymbol{n} \mathbf{( \% )}\end{array}$ & $\begin{array}{c}\text { Patient Related } \\
\text { Burnout } \\
\boldsymbol{n} \mathbf{( \% )}\end{array}$ \\
\hline $\begin{array}{c}\text { Avoidant coping } \\
\text { Behavioural disengagement }\end{array}$ & & & \\
Yes & $60(90.9)$ & $62(93.9)$ & $46(69.7)$ \\
No & $493(71.7)$ & $459(66.7)$ & $281(40.8)$ \\
Denial & & & \\
Yes & $52(86.7)$ & $52(86.7)$ & $43(71.7)$ \\
No & $501(72.2)$ & $469(67.6)$ & $284(40.9)$ \\
Self-blame & $210(86.8)$ & $200(82.6)$ & $126(52.1)$ \\
No & $343(67.0)$ & $321(62.7)$ & $201(39.3)$ \\
Self-distraction & & & \\
Yes & $375(78.0)$ & $355(73.8)$ & $229(47.6)$ \\
No & $178(65.2)$ & $166(60.8)$ & $98(35.9)$ \\
Yes & $17(89.5)$ & $19(100)$ & $16(84.2)$ \\
No & $536(72.9)$ & $502(68.3)$ & $311(42.3)$ \\
\hline
\end{tabular}

\subsection{Relationship between Training Characteristics and Burnout}

As illustrated in Table 3, we found no significant relationship between length of experience in internship and burnout. However, emergency medicine interns were more likely than others to have patient-related burnout (54.3\% versus $42.1 \%$; OR: $1.64 ; 95 \% \mathrm{CI}$ : 1.03-2.60), while anesthesiology interns were less likely to experience patient-related burnout ( $21.9 \%$ vs. $44.3 \%$; OR: 0.35 ; $95 \%$ CI: $0.15-0.82)$.

Table 3. Relationship between training characteristics, personal demographics, undergraduate training background and avoidant coping with burnout $(n=754)$.

\begin{tabular}{|c|c|c|}
\hline & Crude Odds Ratio $(95 \%$ CI) * & $p$-Values $* *$ \\
\hline \multicolumn{3}{|l|}{ Personal related burnout } \\
\hline \multicolumn{3}{|l|}{ Personal demographics } \\
\hline Irregular spirituality routines & $1.69(1.18-2.43)$ & 0.004 \\
\hline Higher resilience score & $0.89(0.86-0.91)$ & $<0.001$ \\
\hline \multicolumn{3}{|l|}{ Avoidant coping } \\
\hline Behavioural disengagement & $3.96(1.68-9.31)$ & 0.002 \\
\hline Self-blame & $3.23(2.14-4.90)$ & $<0.001$ \\
\hline Denial & $2.50(1.17-5.37)$ & 0.018 \\
\hline Self-distraction & $1.89(1.36-2.63)$ & $<0.001$ \\
\hline \multicolumn{3}{|l|}{ Work related burnout } \\
\hline \multicolumn{3}{|l|}{ Personal demographics } \\
\hline Irregular spirituality routines & $1.86(1.32-2.64)$ & $<0.001$ \\
\hline Higher resilience score & $0.88(0.85-0.90)$ & $<0.001$ \\
\hline \multicolumn{3}{|l|}{ Avoidant coping } \\
\hline Behavioural disengagement & $7.73(2.78-21.52)$ & $<0.001$ \\
\hline Denial & $3.12(1.46-6.68)$ & 0.003 \\
\hline Self-blame & $2.83(1.94-4.13)$ & $<0.001$ \\
\hline Self-distraction & $1.82(1.32-2.49)$ & $<0.001$ \\
\hline \multicolumn{3}{|l|}{ Patient related burnout } \\
\hline \multicolumn{3}{|l|}{ Training characteristics } \\
\hline Emergency Medicine & $1.64(1.03-2.60)$ & 0.037 \\
\hline Anaesthesiology & $0.35(0.15-0.82)$ & 0.016 \\
\hline \multicolumn{3}{|l|}{ Personal demographics } \\
\hline No extracurricular involvements in & & \\
\hline $\begin{array}{l}\text { undergraduate years } \\
\text { Lived with someone at home }\end{array}$ & $\begin{array}{l}1.38(1.04-1.85) \\
1.56(1.06-2.28)\end{array}$ & $\begin{array}{l}0.028 \\
0.023\end{array}$ \\
\hline
\end{tabular}


Table 3. Cont.

\begin{tabular}{lcc}
\hline & Crude Odds Ratio (95\% CI) * & $p$-Values ** \\
\hline $\begin{array}{l}\text { Higher resilience score } \\
\text { Avoidant coping }\end{array}$ & $0.90(0.88-0.93)$ & $<0.001$ \\
Substance abuse & $7.27(2.10-25.17)$ & 0.002 \\
Denial & $3.65(2.04-6.53)$ & $<0.001$ \\
Behavioural disengagement & $3.33(1.93-5.75)$ & $<0.001$ \\
Self-blame & $1.68(1.24-2.29)$ & 0.001 \\
Self-distraction & $1.62(1.20-2.20)$ & 0.002 \\
\hline
\end{tabular}

Abbreviations: CI, confidence interval; OR: odds ratio; 95\% CI: 95\% confidence interval. ${ }^{*}$ With the exception of resilience score, the odds ratio reflects the ratio of burnout occurring in the described cohort to the ratio of burnout on the other cohort. For resilience score, the odds ratio reflects the ratio of burnout associated with one score increased in CD-RISC instrument. ${ }^{* *}$ Only variables that are statistically significant $(p$-value $<0.05)$ shown in the table.

\subsection{Relationship between Personal Demographics and Burnout}

Interns who had irregular spirituality routines were more likely than others to experience personal-related burnout $(79.8 \%$ versus $70.1 \%$; OR: $1.69 ; 95 \%$ CI: $1.18-2.43)$ and work-related burnout (77.5\% vs. $64.9 \%$; OR, $1.86 ; 95 \%$ CI, $1.32-2.64)$. No other significant relationship was found for personal- and work-related burnout. Interns who lived with someone at home and interns who had no extracurricular involvements in their undergraduate years were more likely than others to experience patient-related burnout (45.4\% versus $34.8 \%$; OR: 1.56 ; $95 \%$ CI: $1.06-2.28$ and $47.8 \%$ versus $39.8 \%$; OR: 1.38 ; $95 \%$ CI: 1.04-1.85, respectively). We found no significant relationship between gender, marital status, undergraduate results, or prior work experience with any domain of burnout.

\subsection{Relationship between Undergraduate Training Background and Burnout}

We found no significant relationship between undergraduate training background and intern shadowing with burnout.

\subsection{Relationship between Resilience and Burnout}

The mean CD-RISC score in this sample was 31.75 with a standard deviation of 6.39 . Consistent with the conceptual framework, we found that with one-point increase of CDRISC score the odds ratio of burnout decreased for personal-related burnout (OR, 0.89; $95 \%$ CI, $0.86-0.91$ ), work-related burnout (OR, 0.88 ; 95\% CI, $0.85-0.90)$, and patient-related burnout (OR, 0.90; 95\% CI, 0.88-0.93).

\subsection{Relationship between Avoidant Coping and Burnout}

Interns who utilized avoidant coping, such as behavioral disengagement, denial, selfblame, and self-distraction, were 1.62 to 7.73 times more likely than others to experience all three domains of burnout (Table 3). Interns who utilized substance abuse coping were 7.27 times more likely than others to experience patient-related burnout $(84.2 \%$ versus 42.3\%; OR: 7.27; 95\% CI: 2.10-25.17).

\subsection{Multivariable Analysis of Burnout}

Significant relationships are shown in Table 4. Through multivariable analysis, we found that self-blame (OR, 2.63; 95\% CI: 1.66-4.19), self-distraction (OR, 1.99; 95\% CI: 1.37-2.89), irregular spirituality routines (OR, 1.97; 95\% CI: 1.30-2.99), prior work experience (OR, 1.56; 95\% CI: 1.05-2.30), being female (OR, 1.50; 95\% CI: 1.02-2.20), or having a lower resilience score (OR, $0.89 ; 95 \%$ CI: $0.86-0.92)$ were independently associated with personal-related burnout. Behavioral disengagement (OR, 3.24; 95\% CI: 1.06-9.88), self-distraction (OR, 2.04; 95\% CI: 1.42-2.95), self-blame (OR, 1.99; 95\% CI: 1.30-3.06), irregular spirituality routines (OR, 2.24; 95\% CI: 1.493.37), or a lower resilience score (OR, $0.88 ; 95 \% \mathrm{CI}, 0.85-0.90)$ remained independently associated with work-related burnout. Substance abuse (OR, 4.09; 95\% CI: 1.06-15.78), denial (OR, 3.01; 95\% CI: 1.55-5.83), selfdistraction (OR, 1.71; 95\% CI: 1.21-2.40), living with someone at home (OR, 1.77; 95\% CI: 
1.15-2.73), or having a lower resilience score (OR, 0.91; 95\% CI: 0.88-0.93) were independently associated with patient-related burnout.

Table 4. Significant relationship between studied variables and burnout in a descending odds ratio as analyzed from binary logistic regression $(n=754)$.

\begin{tabular}{|c|c|c|c|}
\hline & Nagelkerke $\mathbf{R}^{2}$ & $\begin{array}{l}\text { Adjusted Odds } \\
\text { Ratio }(95 \% \text { CI) * }\end{array}$ & $p$-Values $* *$ \\
\hline Personal-related burnout & 0.238 & & \\
\hline Avoidant coping: Self blame & & $2.63(1.66-4.19)$ & $<0.001$ \\
\hline Avoidant coping: Self distraction & & $1.99(1.37-2.89)$ & $<0.001$ \\
\hline Irregular spirituality routines & & $1.97(1.30-2.99)$ & 0.002 \\
\hline Prior working experience & & $1.56(1.05-2.30)$ & 0.027 \\
\hline Gender: Female & & $1.50(1.02-2.20)$ & 0.041 \\
\hline Higher resilience score & & $0.89(0.86-0.92)$ & $<0.001$ \\
\hline Work-related burnout & 0.284 & & \\
\hline $\begin{array}{l}\text { Avoidant coping: Behavioural } \\
\text { disengagement }\end{array}$ & & $3.24(1.06-9.88)$ & 0.039 \\
\hline Irregular spirituality routines & & $2.24(1.49-3.37)$ & $<0.001$ \\
\hline Avoidant coping: Self distraction & & $2.04(1.42-2.95)$ & $<0.001$ \\
\hline Avoidant coping: Self blame & & $1.99(1.30-3.06)$ & 0.002 \\
\hline Higher resilience score & & $0.88(0.85-0.90)$ & $<0.001$ \\
\hline Patient-related burnout & 0.201 & & \\
\hline Avoidant coping: Substance abuse & & $4.09(1.06-15.78)$ & 0.041 \\
\hline Avoidant coping: Denial & & $3.01(1.55-5.83)$ & 0.001 \\
\hline Staying with someone at home & & $1.77(1.15-2.73)$ & 0.010 \\
\hline Avoidant coping: Self distraction & & $1.71(1.21-2.40)$ & 0.002 \\
\hline Higher resilience score & & $0.91(0.88-0.93)$ & $<0.001$ \\
\hline
\end{tabular}

Abbreviations: CI, confidence interval; OR, odds ratio; 95\% CI: 95\% confidence interval. ${ }^{*}$ With the exception of resilience score, the odds ratio reflects the ratio of burnout occurring in the described cohort to the ratio of burnout on the other cohort. For resilience score, the odds ratio reflects the ratio of burnout associated with 1 score increased in CD-RISC instrument. ** Only variables that are statistically significant $(p$-value $<0.05)$ shown in the table.

Table 4 also reports the Nagelkerke $\mathrm{R}^{2}$ value that measured the proportion of variance in the proposed models associated with the independent variables. For personal-related burnout, the model explained $23.8 \%$ of the variance and correctly identified $75.9 \%$ of burnout cases. As for work-related burnout, the model explained $28.4 \%$ of the variance and correctly identified $74.1 \%$ of burnout cases. While for patient-related burnout, $20.1 \%$ of the variance and correctly identified $67.0 \%$ of burnout cases.

\section{Discussion}

In this multi-center study, we made several important findings. First, the prevalence of intern burnout was high in all domains. This can be explained by Karasek Job Strain model, which posits that interns are vulnerable to develop burnout due to heavy workload and having little control over their jobs [37]. We found that personal- and work-related burnout prevalence $(73.3 \%$ and $69.1 \%$ respectively) were higher than those in other studies conducted with interns using similar instruments in Australia (36.0\% and $31.0 \%$ respectively) and India $(64.1 \%$ and $40.0 \%$ respectively) [38,39]. Our patient-related burnout $(43.4 \%)$ was lower than that in the study from India (68.6\%) [38] but higher than that found in a single-institution study involving Malaysian medical residents (25.2\%) [40]. Despite stricter implementation of work hour restrictions in the training, we found that the prevalence of burnout in the current study was notably higher than in the previous study [23]. This further supports the concept that long hours are not the sole factor contributing to burnout, and future intervention should address more areas on top of work hours restrictions [10].

In terms of training characteristics, our findings were consistent with recent studies that showed Emergency Medicine physicians were at higher risk to develop burnout [41,42]. Some studies reported a significantly higher burnout prevalence among junior physicians $[5,11,34,43-45]$ while other studies found no difference $[10,46]$. Previous work in Malaysia proposed that burnout was highest in the first six months of internship [10], however our findings suggested that burnout was high in both years of training. In Malaysia, 
interns move to a new rotation every four months, and these lateral moves require them to learn different sets of competencies and adapt to new environment, perpetuating them to cycles of burnout [19].

Some studies have suggested that gender is a weak predictor of burnout, while other studies reported no difference in burnout due to gender [1,7]. Through multivariable analysis, we found that female interns were more likely than males to develop personalrelated burnout, and this seemed to be consistent with two recent studies of interns in the United Kingdom and Australia [34,47]. We did not find any association between marital status and undergraduate academic results with burnout by either univariate or multivariable analysis. The findings on marital status indifferences corroborate with a study from Iran [48]. However, there was scarce literature that discussed academic performance and physician burnout.

In Malaysia, about half of the interns had their undergraduate training abroad and faced acculturation to the local healthcare system during their internship. Despite working international medical graduates working in an unfamiliar environment, previous studies from the United States proposed that they suffered less fatigue and burnout $[44,49]$. Interns who graduated abroad persevered challenges in different healthcare environment as students. Additionally, more medical schools now incorporate intern shadowing programs to address burnout by facilitating the transition to the work environment [50]. We assessed the relationships of undergraduate training background and intern shadowing with burnout, and, contrary to our hypothesis, we found no significant correlations.

We hypothesized that engagement in activities that enhance interpersonal skills would have a protective effect against burnout. Consistent with another study among undergraduate students [51], we found that involvement in extracurricular activities reduced the risk of developing patient-related burnout. In contrast, through multivariable analysis, we found that interns who had working experience prior to internship were more likely to develop personal-related burnout. While we found no literature explaining this, a study on residents found no association between profession building activities with burnout development in residents [14].

Similar to previous studies in residents [14,52], we found that regular spirituality routines lowered the risk of developing personal- and work-related burnout among interns. Spirituality routines have been increasingly recognized as a source of comfort and hope during adversities and have been positively correlated with job commitment [53]. Social support at work has been linked with burnout reduction [1,44]. While several studies found no link between social support at home with burnout $[10,14,48]$, our findings revealed that interns who lived with someone at home were at higher risk to develop patientrelated burnout. Work-life balance is recognized as one of the major stressors among physicians $[7,18]$. Although a family, spouse or housemate could function as a resource of support, they could also be a source of emotional strain for interns [1]. Another possible explanation is that interns spend more time trying to improve their competency, studying for assessment or recuperating from their work, thus struggling to spare some time with family members, spouse or housemates. This could contribute to exhaustion and detachment from patients and should be part of the assessment in evaluating intern burnout.

Our data also showed that interns who had higher resilience level experienced less burnout. This further supports previous studies that highlighted the negative correlation of resilience with burnout $[54,55]$. Resilient physicians were shown to generate positive resource spirals through self-care, reflection, and active engagement with their own limitation [55].

The most striking findings in this study was the significant relationship between avoidant coping strategies with all domains of burnout. We found that $63.8 \%$ interns utilized self-distraction as one of their coping mechanisms and they were twice as likely to develop burnout. The findings were also in agreement with similar studies conducted with other regions [14,56]. As coping strategies explained $5.4 \%$ of the variance in burnout development [56], our data further supports the value of individuals-targeted intervention along- 
side organization-directed intervention [7,57]. Described individuals-targeted intervention includes stress management, self-care efforts, coping, and mindfulness training $[7,58]$. Educational intervention such as coping skills training have shown some effectiveness in enhancing resilience [59] and should be integrated in the personal development programs.

The study provides some important findings that may guide curriculum developers in rethinking the focus of medical training in enhancing the work preparedness of graduates. We echo the call of the Accreditation Council for Graduate Medical Education for internship training programs to focus on well-being [60]. Support at home may not be available or as effective for some interns. Hence, a formal support system through mentoring or support groups should be made available at the workplace. A useful framework to reduce burnout include the Stanford professional fulfilment model that promotes a culture of resilience and well-being in the workplace through reflective groups and healthy work habits, and enhancement of workplace efficiency by improving teamwork, simplifying paper works and reducing bureaucracy [61].

\section{Limitations of Study}

Strengths of this study include the multi-center design that represented the Malaysian intern training landscape, a large sample size and the use of validated instruments. As with other cross-sectional surveys, this study has several limitations. First, we were able to assess only limited personal constructs pertaining to burnout and did not assess for organizational constructs. Second, due to logistic issues, the study utilized convenient sampling, and this might limit its generalizability to a wider context. Third, our study relied on self-reported instruments, and there was potential of reporting bias. Fourth, as the data on coping were treated as dichotomous, certain categories had small numbers of participants resulting in unstable OR with wide CI [62]. Fifth, despite suggesting several significant associations, these relationships do not constitute causal effect. Low resilience levels and avoidant coping strategies could have been the effects of burnout rather than the antecedents. Future studies should include organizational variables (such as work flexibility, support in the workplace and the quality of supervision) or longitudinal studies on individual- and organizational-directed interventions that suit the nature of the interns' work.

\section{Conclusions}

Our findings indicate a high burnout prevalence among Malaysian interns in both years of the training. Certain rotation characteristics, personal variables, low resilience level and avoidant coping were significantly associated with burnout. Burnout is an occupational hazard and active interventions is necessary to prevent adverse impact to the junior doctors, patient care and healthcare system.

Author Contributions: Conceptualization, N.S.R., M.S.B.Y., A.A.R., K.M., N.I.A.S., M.I. and P.B.; methodology, N.S.R., M.S.B.Y., A.A.R. and K.M.; validation, N.S.R. and M.S.B.Y.; investigation and data curation, N.S.R., A.K., N.R., C.R.W.A., M.F.S.B., A.S.A.M., N.H.M.Y.; formal analysis, N.S.R., M.S.B.Y., A.A.R., K.M., N.I.A.S., M.I. and P.B.; writing-original draft preparation, writingreview and editing, N.S.R., M.S.B.Y., A.A.R., K.M., N.I.A.S., A.K., N.R., C.R.W.A., M.F.S.B., A.S.A.M., N.H.M.Y., M.I. and P.B. All authors have read and agreed to the published version of the manuscript.

Funding: This research was funded by University Sains Malaysia (USM) short-term grant 304/PPSP/ 6315214.

Institutional Review Board Statement: This study was conducted according to the guidelines of the Declaration of Helsinki and approved by the Medical Research and Ethics Committee from the Ministry of Health Malaysia (NMRR-20-626-54485), Universiti Sains Malaysia (18020105), and University Malaya (2018521-6308).

Informed Consent Statement: Informed consent was obtained from all subjects involved in the study.

Data Availability Statement: The data presented in this study are available on request from the corresponding author. 
Acknowledgments: We would like to thank the Director General of Health Malaysia for his permission to publish the findings.

Conflicts of Interest: The authors declare no conflict of interest.

\section{References}

1. Maslach, C.; Schaufeli, W.B.; Leiter, M.P. Job Burnout. Annu. Rev. Psychol. 2001, 52, 397-422. [CrossRef]

2. $\quad$ Lin, M.; Battaglioli, N.; Melamed, M.; Mott, S.E.; Chung, A.S.; Robinson, D.W. High Prevalence of Burnout Among US Emergency Medicine Residents: Results From the 2017 National Emergency Medicine Wellness Survey. Ann. Emerg. Med. 2019, 74, 682-690. [CrossRef]

3. Rotenstein, L.S.; Torre, M.; Ramos, M.A.; Rosales, R.C.; Guille, C.; Sen, S.; Mata, D.A. Prevalence of Burnout among Physicians a Systematic Review. J. Am. Med. Assoc. 2018, 320, 1131-1150. [CrossRef]

4. Beyond Blue. National Mental Health Survey of Doctors and Medical Students; Beyond Blue: Melbourne, Australia, 2013.

5. Dyrbye, L.; West, C.P.; Satele, D.; Boone, S.; Tan, L.; Sloan, J.; Shanafelt, T.D. Burnout Among U.S. Medical Students, Residents, and Early Career Physicians Relative to the General U.S. Population. Acad. Med. 2014, 89, 443-451. [CrossRef] [PubMed]

6. Colon, A.; Gillihan, R.; Motaparthi, K. Factors Contributing to Burnout in Dermatologists. Clin. Dermatol. 2020, $38,321-327$. [CrossRef] [PubMed]

7. West, C.P.; Dyrbye, L.N.; Shanafelt, T.D. Physician Burnout: Contributors, Consequences and Solutions. J. Intern. Med. 2018, 283, 516-529. [CrossRef] [PubMed]

8. Salyers, M.P.; Bonfils, K.A.; Luther, L.; Firmin, R.L.; White, D.A.; Adams, E.L.; Rollins, A.L. The Relationship Between Professional Burnout and Quality and Safety in Healthcare: A Meta-Analysis. J. Gen. Intern. Med. 2016, 32, 475-482. [CrossRef]

9. Shanafelt, T.D.; Boone, S.; Tan, L.; Dyrbye, L.N.; Sotile, W.; Satele, D.; West, C.P.; Sloan, J.; Oreskovich, M.R. Burnout and Satisfaction with Work-Life Balance among US Physicians Relative to the General US Population. Arch. Intern. Med. 2012, 172, 1377-1385. [CrossRef]

10. Nishimura, Y.; Miyoshi, T.; Obika, M.; Ogawa, H.; Kataoka, H.; Otsuka, F. Factors Related to Burnout in Resident Physicians in Japan. Int. J. Med. Educ. 2019, 10, 129-135. [CrossRef]

11. Del Carmen, M.G.; Herman, J.; Rao, S.; Hidrue, M.K.; Ting, D.; Lehrhoff, S.R.; Lenz, S.; Heffernan, J.; Ferris, T.G. Trends and Factors Associated with Physician Burnout at a Multispecialty Academic Faculty Practice Organization. JAMA Netw. Open 2019, 2, e190554. [CrossRef]

12. McManus, I.C.; Keeling, A.; Paice, E. Stress, Burnout and Doctors' Attitudes to Work Are Determined by Personality and Learning Style: A Twelve-Year Longitudinal Study of UK Medical Graduates. BMC Med. 2004, 2, 1-12. [CrossRef] [PubMed]

13. Bohman, B.; Dyrbye, L.; Sinsky, C.A.; Linzer, M.; Olson, K.; Babbott, S.; Murphy, L.; Hamidi, M.S. Physician Well-Being: The Reciprocity of Practice Efficiency, Culture of Wellness, and Personal Resilience. N. Engl. J. Med. Catal. 2017, 3, 1-4. [CrossRef]

14. Doolittle, B.R.; Windish, D.M.; Seelig, C.B. Burnout, Coping, and Spirituality Among Internal Medicine Resident Physicians. J. Grad. Med. Educ. 2013, 5, 257-261. [CrossRef] [PubMed]

15. Shoua-Desmarais, N.; von Harscher, H.; Rivera, M.; Felix, T.; Havas, N.; Rodriguez, P.; Castro, G.; Zwingli, E. First Year Burnout and Coping in One US Medical School. Acad. Psychiatry 2020, 44, 394-398. [CrossRef]

16. Nik Ahmad, N.M.A.; Roslan, N.S.; Ismail, S.B.; Nayak, R.D.; Jamian, M.R.; Mohamad Ali Roshidi, A.S.; Edward, T.C.; Kamal, M.A.; Mohd Amin, M.M.; Shaari, S.; et al. Prevalence and Associated Factors of Psychological Distress and Burnout among Medical Students: Findings from Two Campuses. Int. J. Environ. Res. Public Health 2021, 18, 8446. [CrossRef]

17. Yeo, H.; Bucholz, E.; Ann Sosa, J.; Curry, L.; Lewis, F.R.; Jones, A.T.; Viola, K.; Lin, Z.; Bell, R.H. A National Study of Attrition in General Surgery Training: Which Residents Leave and Where Do They Go? Ann. Surg. 2010, 252, 131-139. [CrossRef] [PubMed]

18. Hannan, E.; Breslin, N.; Doherty, E.; McGreal, M.; Moneley, D.; Offiah, G. Burnout and Stress amongst Interns in Irish Hospitals: Contributing Factors and Potential Solutions. Ir. J. Med. Sci. 2018, 187, 301-307. [CrossRef] [PubMed]

19. Dunford, B.B.; Shipp, A.J.; Boss, R.W.; Angermeier, I.; Boss, A.D. Is Burnout Static or Dynamic? A Career Transition Perspective of Employee Burnout Trajectories. J. Appl. Psychol. 2012, 97, 637-650. [CrossRef]

20. Malaysian Medical Council. A Guidebook for House Officer; Malaysian Medical Council: Kuala Lumpur, Malaysia, 2008.

21. Parliament of Malaysia. Medical (Amendment) Act 2012; Dewan Negara: Kuala Lumpur, Malaysia, 2012.

22. Thomas, N.K. Resident Burnout. JAMA 2016, 292, 2880-2889. [CrossRef]

23. Zuraida, A.; Zainal, N. Exploring Burnout Among Malaysian Junior Doctors Using the Abbreviated Maslach Burnout Inventory. Malays. J. Psychiatry 2015, 24, 1-10.

24. Dare, A.; Fancourt, N.; Robinson, E.; Wilkinson, T.; Bagg, W. Training the Intern: The Value of a Pre-Intern Year in Preparing Students for Practice. Med. Teach. 2009, 31, e345-e350. [CrossRef]

25. Van Hamel, C.; Jenner, L.E. Prepared for Practice? A National Survey of UK Foundation Doctors and Their Supervisors. Med. Teach. 2015, 37, 181-188. [CrossRef]

26. Sedgwick, P. Stratified Cluster Sampling. BMJ 2013, 347, 1-2. [CrossRef]

27. Chua, L.C. Sample Size Estimation Using Krejcie and Morgan and Cohen Statistical Power Analysis: A Comparison. J. Penyelid. IPBL 2006, 7, 78-86.

28. Rowe, A.K.; Lama, M.; Onikpo, F.; Deming, M.S. Design Effects and Intraclass Correlation Coefficients from a Health Facility Cluster Survey in Benin. Int. J. Qual. Health Care 2002, 14, 521-523. [CrossRef] [PubMed] 
29. Department of Statistics Malaysia. Population Distribution and Basic Demographic Characteristic Report 2010. Available online: http:/ / www.statistics.gov.my/ (accessed on 25 May 2021).

30. Campbell-Sills, L.; Stein, M. Psychometric Analysis and Refinement of the Connor-Davidson Resilience Scale (CD-RISC): Validation of a 10-Item Measure of Resilience. J. Trauma. Stress 2007, 20, 1019-1028. [CrossRef]

31. Carver, C.S. You Want to Measure Coping But Your Protocol's Too Long: Consider the Brief COPE. Int. J. Behav. Med. 1997, 4, 92-100. [CrossRef] [PubMed]

32. Kristensen, T.S.; Borritz, M.; Villadsen, E.; Christensen, K.B. The Copenhagen Burnout Inventory: A New Tool for the Assessment of Burnout. Work Stress 2005, 19, 192-207. [CrossRef]

33. Baumstarck, K.; Alessandrini, M.; Hamidou, Z.; Auquier, P.; Leroy, T.; Boyer, L. Assessment of Coping: A New French Four-Factor Structure of the Brief COPE Inventory. Health Qual. Life Outcomes 2017, 15, 1-9. [CrossRef]

34. Thrush, C.R.; Guise, J.B.; Gathright, M.M.; Messias, E.; Flynn, V.; Belknap, T.; Thapa, P.B.; Williams, D.K.; Nada, E.M.; Clardy, J.A. A One-Year Institutional View of Resident Physician Burnout. Acad. Psychiatry 2019, 43, 361-368. [CrossRef] [PubMed]

35. Galesic, M. Dropouts on the Web: Effects of Interest and Burden Experienced During an Online Survey. J. Off. Stat. 2006, 22, 313-328.

36. Planning Division Ministry of Health Malaysia. Human Resources for Health Country Profiles 2015 Malaysia; Ministry of Health: Putrajaya, Malaysia, 2015.

37. Karasek, R. Job Demands, Job Decision Latitude and Mental Strain: Implications for Job Redesign. Adm. Sci. Q. 1979, 24, 285-306. [CrossRef]

38. Ratnakaran, B.; Prabhakaran, A.; Karunakaran, V. Prevalence of Burnout and Its Correlates among Residents in a Tertiary Medical Center in Kerala, India: A Cross-Sectional Study. J. Postgrad. Med. 2016, 62, 157-161. [CrossRef] [PubMed]

39. Parr, J.M.; Pinto, N.; Hanson, M.; Meehan, A.; Moore, P.T. Medical Graduates, Tertiary Hospitals, and Burnout: A Longitudinal Cohort Study. Ochsner J. 2016, 16, 22-26. [PubMed]

40. Ali, N.F.; Nasution Raduan, N.J.; Ismail, Z.; Razali, S. Burnout and Coping Skills amongst Medical Officers: A Study in a Tertiary Hospital in Malaysia. Environ. Proc. J. 2019, 4, 141. [CrossRef]

41. Shanafelt, T.D.; West, C.P.; Sinsky, C.; Trockel, M.; Tutty, M.; Satele, D.V.; Carlasare, L.E.; Dyrbye, L.N. Changes in Burnout and Satisfaction with Work-Life Integration in Physicians and the General US Working Population Between 2011 and 2017. Mayo Clin. Proc. 2019, 94, 1681-1694. [CrossRef] [PubMed]

42. Kansoun, Z.; Boyer, L.; Hodgkinson, M.; Villes, V.; Lançon, C.; Fond, G. Burnout in French Physicians: A Systematic Review and Meta-Analysis. J. Affect. Disord. 2019, 246, 132-147. [CrossRef]

43. Shaikh, A.A.; Shaikh, A.; Rajesh, D.; Tahir, A. Assessment of Burnout and Its Factors Among Doctors Using the Abbreviated Maslach Burnout Inventory. Cureus 2019, 11. [CrossRef]

44. Sun, H.; Warner, D.O.; Macario, A.; Zhou, Y.; Culley, D.J.; Keegan, M.T. Repeated Cross-Sectional Surveys of Burnout, Distress, and Depression among Anesthesiology Residents and First-Year Graduates. Anesthesiology 2019, 131, 668-677. [CrossRef]

45. Roth, M.; Morrone, K.; Moody, K.; Kim, M.; Wang, D.; Moadel, A.; Levy, A. Career Burnout Among Pediatric Oncologists Michael. Pediatr. Blood Cancer 2011, 57, 1168-1173. [CrossRef]

46. AlSayari, R.A. Using Single-Item Survey to Study the Prevalence of Burnout among Medical Residents-Influence of Gender and Seniority. Saudi J. Kidney Dis. Transplant. 2019, 30, 581-586. [CrossRef]

47. Monrouxe, L.V.; Bullock, A.; Tseng, H.M.; Wells, S.E. Association of Professional Identity, Gender, Team Understanding, Anxiety and Workplace Learning Alignment with Burnout in Junior Doctors: A Longitudinal Cohort Study. BMJ Open 2017, 7, 1-12. [CrossRef] [PubMed]

48. Yazdi, Z.; Abbasi, M.; Kazemifar, A.M. Prevalence of Burnout Syndrome in the Beginning and End of Internship Course in Medical Students of Qazvin University of Medical Sciences. J. Med. Educ. 2018, 17, 1-8. [CrossRef]

49. Gozu, A.; Kern, D.E.; Wright, S.M. Similarities and Differences between International Medical Graduates and U.S. Medical Graduates at Six Maryland Community-Based Internal Medicine Residency Training Programs. Acad. Med. 2009, 84, 385-390. [CrossRef]

50. Kitsis, E.A.; Goldsammler, M. Physician Shadowing: A Review of the Literature and Proposal for Guidelines. Acad. Med. 2013, 88, 102-110. [CrossRef] [PubMed]

51. Fares, J.; Al Tabosh, H.; Saadeddin, Z.; El Mouhayyar, C.; Aridi, H. Stress, Burnout and Coping Strategies in Preclinical Medical Students. N. Am. J. Med. Sci. 2016, 8, 75-81. [CrossRef] [PubMed]

52. Watson, A.G.; Saggar, V.; MacDowell, C.; McCoy, J.V. Self-Reported Modifying Effects of Resilience Factors on Perceptions of Workload, Patient Outcomes, and Burnout in Physician-Attendees of an International Emergency Medicine Conference. Psychol. Health Med. 2019, 24, 1220-1234. [CrossRef] [PubMed]

53. Malik, S.; Riaz, N.; Nazir, S. Personal Spirituality and Work Attitudes Among Doctors. J. Behav. Sci. 2015, 25, 136-149.

54. Buck, K.; Williamson, M.; Ogbeide, S.; Norberg, B. Family Physician Burnout and Resilience: A Cross-Sectional Analysis. Fam. Med. 2019, 51, 657-663. [CrossRef] [PubMed]

55. Zwack, J.; Schweitzer, J. If Every Fifth Physician Is Affected by Burnout, What about the Other Four? Resilience Strategies of Experienced Physicians. Acad. Med. 2013, 88, 382-389. [CrossRef]

56. Lue, B.H.; Chen, H.J.; Wang, C.W.; Cheng, Y.; Chen, M.C. Stress, Personal Characteristics and Burnout among First Postgraduate Year Residents: A Nationwide Study in Taiwan. Med. Teach. 2010, 32, 400-407. [CrossRef] [PubMed] 
57. De Simone, S.; Vargas, M.; Servillo, G. Organizational Strategies to Reduce Physician Burnout: A Systematic Review and Meta-Analysis. Aging Clin. Exp. Res. 2019, 33, 883-894. [CrossRef]

58. Patel, U.; Zhang, M.; Patel, K.; Malik, P.; Shah, M.; Rasul, B.; Habib, A.; Lavado, L.; Kavi, T.; Tadi, P.; et al. Recommended Strategies for Physician Burnout, a Well-Recognized Escalating Global Crisis among Neurologists. J. Clin. Neurol. 2020, 16, 191-201. [CrossRef] [PubMed]

59. Kunzler, A.M.; Helmreich, I.; Chmitorz, A.; König, J.; Binder, H.; Wessa, M.; Lieb, K. Psychological Interventions to Foster Resilience in Healthcare Professionals. Cochrane Database Syst. Rev. 2020, 7, CD012527. [CrossRef] [PubMed]

60. Accreditation Council for Graduate Medical Education. Improving Physician Well-Being, Restoring Meaning in Medicine. Available online: https:/ / www.acgme.org/ (accessed on 25 May 2021).

61. Olson, K.; Marchalik, D.; Farley, H.; Dean, S.M.; Lawrence, E.C.; Hamidi, M.S.; Rowe, S.; McCool, J.M.; O’Donovan, C.A.; Micek, M.A.; et al. Organizational Strategies to Reduce Physician Burnout and Improve Professional Fulfillment. Curr. Probl. Pediatr. Adolesc. Health Care 2019, 49, 100664. [CrossRef]

62. Dyrbye, L.N.; Massie, F.S.; Eacker, A.; Harper, W.; Power, D.; Durning, S.J.; Thomas, M.R.; Moutier, C.; Satele, D.; Sloan, J.; et al. Relationship between Burnout and Professional Conduct and Attitudes among US Medical Students. JAMA 2010, 304, 1173-1180. [CrossRef] 